\title{
RESEARCH
}

Open Access

\section{Survival by colon cancer stage and screening interval in Lynch syndrome: a prospective Lynch syndrome database report}

Mev Dominguez-Valentin ${ }^{1 *+}$ (D), Toni T. Seppälä ${ }^{2,3 \dagger}$, Julian R. Sampson ${ }^{4}$, Finlay Macrae, ${ }^{5,6}$, Ingrid Winship ${ }^{5,6}$, D. Gareth Evans ${ }^{7}$, Rodney J. Scott ${ }^{8}$, John Burn ${ }^{9}$, Gabriela Möslein ${ }^{10}$, Inge Bernstein ${ }^{11}$, Kirsi Pylvänäinen ${ }^{12}$, Laura Renkonen-Sinisalo 2,13, Anna Lepistö ${ }^{2,13}$, Annika Lindblom ${ }^{14}$, John-Paul Plazzer ${ }^{5}$, Douglas Tjandra ${ }^{6}$, Huw Thomas ${ }^{15}$, Kate Green ${ }^{7}$, Fiona Lalloo ${ }^{7}$, Emma J. Crosbie ${ }^{16}$, James Hill ${ }^{7}$, Gabriel Capella ${ }^{17,18}$, Marta Pineda ${ }^{17,18}$, Matilde Navarro ${ }^{17,18}$, Joan Brunet Vidal ${ }^{17,18}$, Karina Rønlund ${ }^{19}$, Randi Thyregaard Nielsen ${ }^{20}$, Mette Yilmaz ${ }^{21}$, Louise Laurberg Elvang ${ }^{22}$, Lior Katz ${ }^{23}$, Maartje Nielsen ${ }^{24}$, Sanne W. ten Broeke ${ }^{24}$, Sigve Nakken ${ }^{1}$, Eivind Hovig ${ }^{1,25}$, Lone Sunde ${ }^{26}$, Matthias Kloor ${ }^{27,28}$, Magnus v Knebel Doeberitz ${ }^{27,28}$, Aysel Ahadova ${ }^{27,28}$, Noralane Lindor ${ }^{29}$, Verena Steinke-Lange ${ }^{30,31}$, Elke Holinski-Feder ${ }^{30,31}$, Jukka-Pekka Mecklin ${ }^{32,33}$ and Pål Møller ${ }^{1}$

\footnotetext{
Abstract

Background: We previously reported that in pathogenic mismatch repair (path_MMR) variant carriers, the incidence of colorectal cancer (CRC) was not reduced when colonoscopy was undertaken more frequently than once every 3 years, and that CRC stage and interval since last colonoscopy were not correlated.

Methods: The Prospective Lynch Syndrome Database (PLSD) that records outcomes of surveillance was examined to determine survival after colon cancer in relation to the time since previous colonoscopy and pathological stage. Only path_MMR variants scored by the InSiGHT variant database as class 4 or 5 (clinically actionable) were included in the analysis.

Results: Ninety-nine path_MMR carriers had no cancer prior to or at first colonoscopy, but subsequently developed colon cancer. Among these, 96 were 65 years of age or younger at diagnosis, and included 77 path_MLH1, 17 path_ MSH2, and 2 path_MSH6 carriers. The number of cancers detected within $<1.5,1.5-2.5,2.5-3.5$ and at $>3.5$ years after previous colonoscopy were 9, 43, 31 and 13, respectively. Of these, 2, 8, 4 and 3 were stage III, respectively, and only one stage IV (interval 2.5-3.5 years) disease. Ten-year crude survival after colon cancer were 93, 94 and 82\% for stage I, II and III disease, respectively $(p<0.001)$. Ten-year crude survival when the last colonoscopy had been $<1.5,1.5-2.5$, 2.5-3.5 or $>3.5$ years before diagnosis, was $89,90,90$ and $92 \%$, respectively $(p=0.91)$.

(Continued on next page)
}

\footnotetext{
*Correspondence: mev_dv@yahoo.com; Mev.Dominguez.Valentin@rrresearch.no

${ }^{\dagger}$ Mev Dominguez-Valentin and Toni T. Seppälä contributed equally to this work.

${ }^{1}$ Department of Tumor Biology, Institute of Cancer Research, Oslo University Hospital, Oslo, Norway

Full list of author information is available at the end of the article
}

(c) The Author(s). 2019 Open Access This article is distributed under the terms of the Creative Commons Attribution 4.0 International License (http://creativecommons.org/licenses/by/4.0/), which permits unrestricted use, distribution, and reproduction in any medium, provided you give appropriate credit to the original author(s) and the source, provide a link to the Creative Commons license, and indicate if changes were made. The Creative Commons Public Domain Dedication waiver (http://creativecommons.org/publicdomain/zero/1.0/) applies to the data made available in this article, unless otherwise stated. 
(Continued from previous page)

Conclusions: In path_MLH1 and path_MSH2 carriers, more advanced colon cancer stage was associated with poorer survival, whereas time since previous colonoscopy was not. Although the numbers are limited, together with our previously reported findings, these results may be in conflict with the view that follow-up of path_MMR variant carriers with colonoscopy intervals of less than 3 years provides significant benefit.

Keywords: Lynch syndrome, Survival, Colonoscopy, Surveillance, Cancer stage, Colon cancer,

\section{Background}

Initially, colonoscopy every third year was advocated to prevent death from colorectal cancer (CRC) in Lynch Syndrome (LS), whereas more recent clinical guidelines suggest colonoscopy at least once every 2 years, beginning between 20 and 25 years of age [1]. However, we have recently reported that for pathogenic mismatch repair (path_MMR) variant carriers, 1-2 yearly colonoscopy surveillance strategies do not result in a lower incidence of $\mathrm{CRC}$, compared to a three-yearly strategy [2]. Recently, the Prospective Lynch Syndrome Database (PLSD) reported CRC stage data from 9 countries showing that 1-2 yearly colonoscopy was not associated with a diagnosis of CRC at an earlier stage than 3-yearly colonoscopy [2]. These findings were consistent with a report of no difference in CRC incidence and stage in LS patients between Germany (where colonoscopy surveillance is performed yearly), the Netherlands (1-2 yearly) or Finland (2-3 yearly) [3].

Geography and differences in follow-up practices might impact cancer risks, although no significant differences were identified in the most recently updated series of the PLSD study, which included 6350 path_MMR carriers who were prospectively observed for 51,646 followup years [4]. A recent single centre and retrospective French study suggested that an optimized colonoscopic surveillance program in LS patients might improve screening quality and possibly decrease CRC occurrence, but long-term prospective studies are needed to confirm these findings [5].

Because the current prospective evidence suggests that annual colonoscopies compared to three yearly colonoscopies do not benefit path_MMR carriers in terms of CRC incidence or earlier cancer stage at diagnosis, we aimed to determine if survival after colon cancer differs according to the intervals of colonoscopies undertaken prior to cancer diagnosis in path_MMR carriers. We also examined the relationship between stage at diagnosis and survival.

\section{Methods}

\section{PLSD design}

PLSD is an international, multi-centre database recording prospective observational data on path_MMR carriers under surveillance by colonoscopy [2, 6-10]. All collaborating centres undertook genetic testing with appropriate informed consents according to local and national requirements. No named data were exported to the PLSD.

\section{Inclusion criteria and statistical analysis}

Inclusion criteria comprised only carriers with variants scored by the InSiGHT variant database (https://www. insight-group.org/variants/databases/) as class 4 and 5 (clinically actionable), and having a colon cancer detected during prospective follow-up. All cancers detected prior to, at or within 1 year after the age at the first planned and performed colonoscopy were scored as prior or prevalent cancers, and were excluded from the analysis when scoring prospectively observed cancers. Rectal cancer was not included because of known timetrends in outcome related to changes in management during the observation period and the low numbers of cases.

The following information was used in the statistical analyses: sex, path_MMR variant, age at inclusion, age at last update, age at death, age at colon cancer, type of cancer as indicated by the first three positions in the International Classification of Diseases version 9 (ICD-9) diagnostic system, the American Joint Committee on Cancer (AJCC) stage of colon cancer (I-IV) and the time since the last colonoscopy preceding the diagnosis of colon cancer. We considered AJCC stage III-IV as advanced [2].

The time elapsed since the colonoscopy before the one at which the cancer diagnosis was made was recorded and categorized, as previously reported [2]. Longer or shorter intervals between colonoscopies than planned may occur for several reasons in the clinical setting, and so we recorded actual time since last colonoscopy. We did not measure compliance with preset protocols, which would have been complex since protocols had changed during the observation period and different centres used different protocols at different times. We also compared time intervals and AJCC stage by MMR gene affected. Statistical testing was performed by SYSTAT13@.

\section{Survival analysis}

Survival after colon cancer was estimated as previously described [6, 7, 9]. Briefly, the Kaplan-Meier survival 
function from first prospectively detected colon cancer diagnosis to death was calculated. To minimize probabilities of death from other causes, survival calculations were restricted to cases diagnosed with colon cancer at 65 years of age or younger.

\section{Results}

Ten centres in nine different countries (Finland, Sweden, Norway, Denmark, The Netherlands, UK, Spain, Israel and Australia) contributed to this study. Together, they reported 196 path_MMR carriers without prior or prevalent colon cancer at inclusion having had prospectively detected colon cancer. Ten of these had had two prospectively detected colon cancers and were excluded, leaving 186 cases with one prospectively detected colon cancer for survival analysis. Among these, 96 path_MMR carriers having had no prior or prevalent cancer in any organ were later prospectively diagnosed with colon cancer at age 65 years or younger. These 96 path_MMR carriers were selected for survival analysis and included 77 path MLH1, 17 path_MSH2 and 2 path_MSH6 carriers.

The numbers of colon cancers detected within $<1.5$, 1.5 to $2.5,2.5$ to 3.5 and $>3.5$ years since previous colonoscopy were $9,43,31$ and 13 , respectively. The median time since previous colonoscopy to colon cancer was 28 months (2.3 years). Only one patient was diagnosed with a stage IV disease (path_MLH1 carrier with a 2.5 to 3.5 years interval, who died within 5 years of diagnosis). Ten path_MLH1 carriers, 7 path_MSH2 carriers, and none of the path_MSH6 carriers were diagnosed with a stage III colon cancer (Table 1). Data on gender and colonoscopy interval broken down by gene are presented in Table 2 .

Five- and 10-year crude survival after colon cancers that were diagnosed before 65 years of age in path MLH1, path_MSH2 and path_MSH6 carriers are presented in Table 3 and Fig. 1. Median follow-up time after prospectively detected colon cancer was 14 years. Ten-year survival when the last colonoscopy had been undertaken $<1.5,1.5-2.5,2.5-3.5$ or $>3.5$ years before diagnosis, was $89,90,90$ and $92 \%$, respectively $(p=0.91)$. Ten year crude survival was $93 \%$ for stage I, $94 \%$ for stage II and $82 \%$ for stage III $(p<0.001)$. There were no significant differences in survival according to which MMR gene was involved $(p=0.90)$.

Table 1 Number of cases by gene and stage

\begin{tabular}{llll}
\hline CRC Stage & path_MLH1 & path_MSH2 & path_MSH6 \\
\hline Stage I & 37 & 7 & 1 \\
Stage II & 29 & 3 & 1 \\
Stage III & 10 & 7 & 0 \\
Stage IV & 1 & 0 & 0 \\
\hline
\end{tabular}

Table 2 Gender and colonoscopy interval distribution by path_MMR gene of the 96 path_MMR carriers included in the study

\begin{tabular}{llll}
\hline Parameter & path_MLH1 & path_MSH2 & path_MSH6 \\
\hline Gender & 41 & 9 & 2 \\
Female & 36 & 8 & 0 \\
Male & & \\
Colonoscopy interval & & 2 & 0 \\
Less than 1.5 years & 7 & 10 & 1 \\
1.5 to 2.5 years & 32 & 1 & 1 \\
2.5 to 3.5 years & 29 & 4 & 0 \\
Over 3.5 years & 9 & & \\
\hline
\end{tabular}

We also performed a sensitivity analysis determining survival according to the time since last colonoscopy by including path_MMR carriers with all prospectively detected colon cancers (i.e. also including those patients with prior or prevalent cancer in other organs, of whom 143 had colon cancer diagnosed at 65 years of age or younger), and arrived at similar results to those for the 96 path_MMR carriers without any prior or prevalent cancer (Fig. 2) i.e. no significant association with time since last colonoscopy $(p=0.93)$; and significant association with stage $(p<0.001)$.

\section{Discussion}

In the current study, we found no demonstrable difference in crude survival after colon cancer in path_MMR carriers who had had their last colonoscopy 3 years before the diagnosis of colon cancer, compared to those with shorter times between last colonoscopy and diagnosed colon cancer. Considered together with our previous reports, in which we found no decrease in the

Table 3 Crude survival (\%) after selected colon cancer diagnosed after initiation of colonoscopy surveillance and before age of 65 years for path_MLH1, path_MSH2 and path_MSH6 carriers with no cancer in any organ prior to, at, or within 1 year of their first colonoscopy

\begin{tabular}{lllll}
\hline Parameter & $\begin{array}{l}\text { 5-year } \\
\text { survival (\%) }\end{array}$ & $95 \% \mathrm{Cl}(\%)$ & $\begin{array}{l}\text { 10-year } \\
\text { survival (\%) }\end{array}$ & $95 \% \mathrm{Cl}(\%)$ \\
\hline $\begin{array}{l}\text { Interval } \\
\text { Less than 1.5 years }\end{array}$ & 89 & {$[43-98]$} & 89 & {$[43-98]$} \\
1.5 to 2.5 years & 95 & {$[83-99]$} & 90 & {$[75-96]$} \\
2.5 to 3.5 years & 94 & {$[77-98]$} & 90 & {$[72-97]$} \\
Over 3.5 years & 92 & {$[57-99]$} & 92 & {$[57-99]$} \\
Stage & & & & \\
I & 98 & {$[84-99.7]$} & 93 & {$[79-98]$} \\
II & 97 & {$[80-99.6]$} & 94 & {$[78-98]$} \\
III & 82 & {$[55-94]$} & 82 & {$[55-94]$} \\
\hline
\end{tabular}

$a_{\mathrm{IV}}$ : One path_MLH1 carrier who died before 5 years 


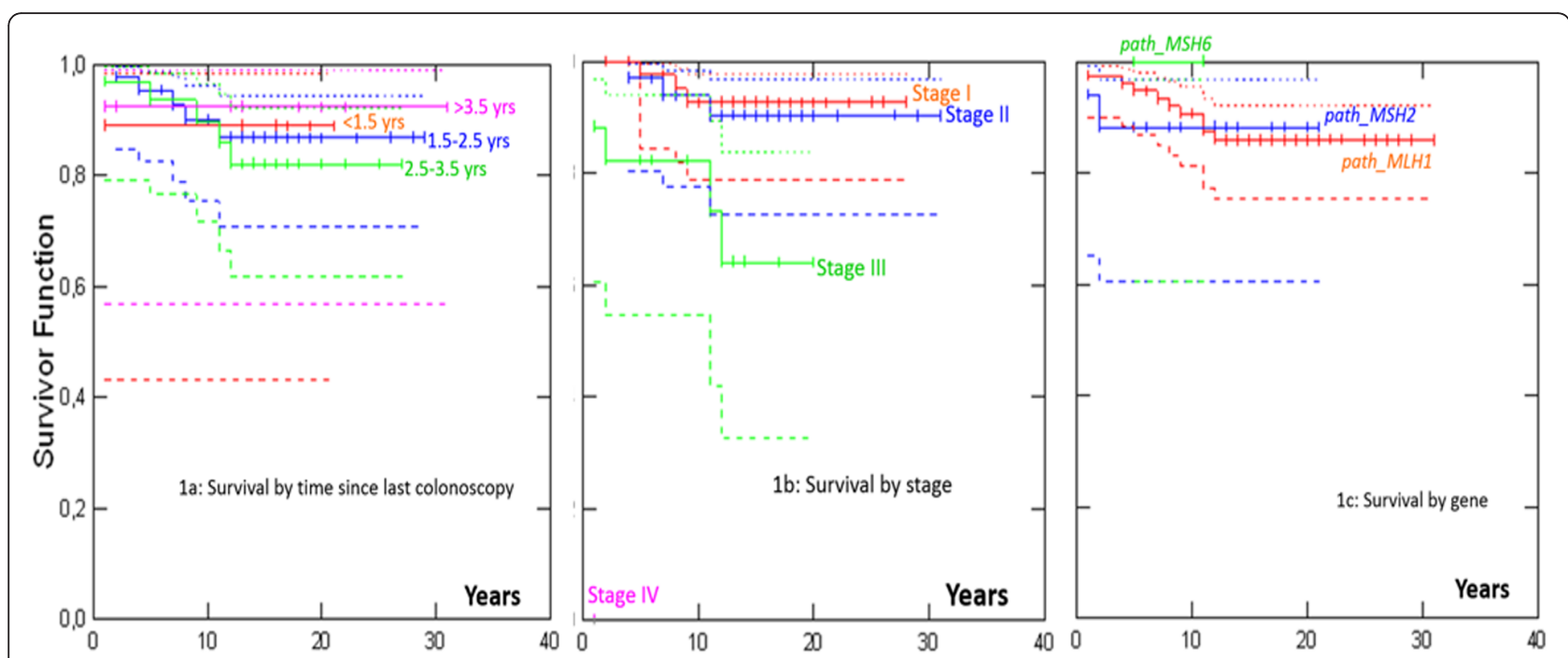

Fig. 1 Survival after colon cancer in 96 path_MMR carriers under 65 years of age without prior or prevalent cancer in any other organ

incidence of CRC with advanced stages of CRCs where the interval since last colonoscopy was less than 3 years before cancer diagnosis, our findings may be considered to be in conflict with the view underlying the current recommendations on the follow up of path_MMR carriers with colonoscopy more often than every 3 years.

In a previous report, we discussed the possibility that not only microsatellite unstable non-invasive lesions, but also infiltrating cancers in LS, may be removed by the host immune system [2]. Aysel Ahadova et al. suggested that although some CRCs in LS may develop from MMR-proficient adenomas after secondary inactivation of the MMR system, a larger portion of LS CRCs appear to develop from MMR deficient crypt foci, either through an adenomatous phase or as non-polyp lesions with immediate invasive growth that may not have colonoscopically visible precursor lesions [11, 12]. Our current report does not aim to provide a full discussion of the biological models that may explain our results: the few we mention are provided to illustrate the wide range of possible explanations that require further investigation.

Our study included only path_MLH1 and path_MSH2 carriers, except for two path_MSH6 carriers, and any conclusions based on this report should be applied to path_MLH1 and path_MSH2 carriers only. Besides, it has already been described that path_PMS2 carriers have almost no incident cancer risk under surveillance.

Clinical guidelines should be based on observed outcomes of interventions. Whatever the reasons for the results presented herein, we report our observed prospective empirical outcomes of clinical guidelines that
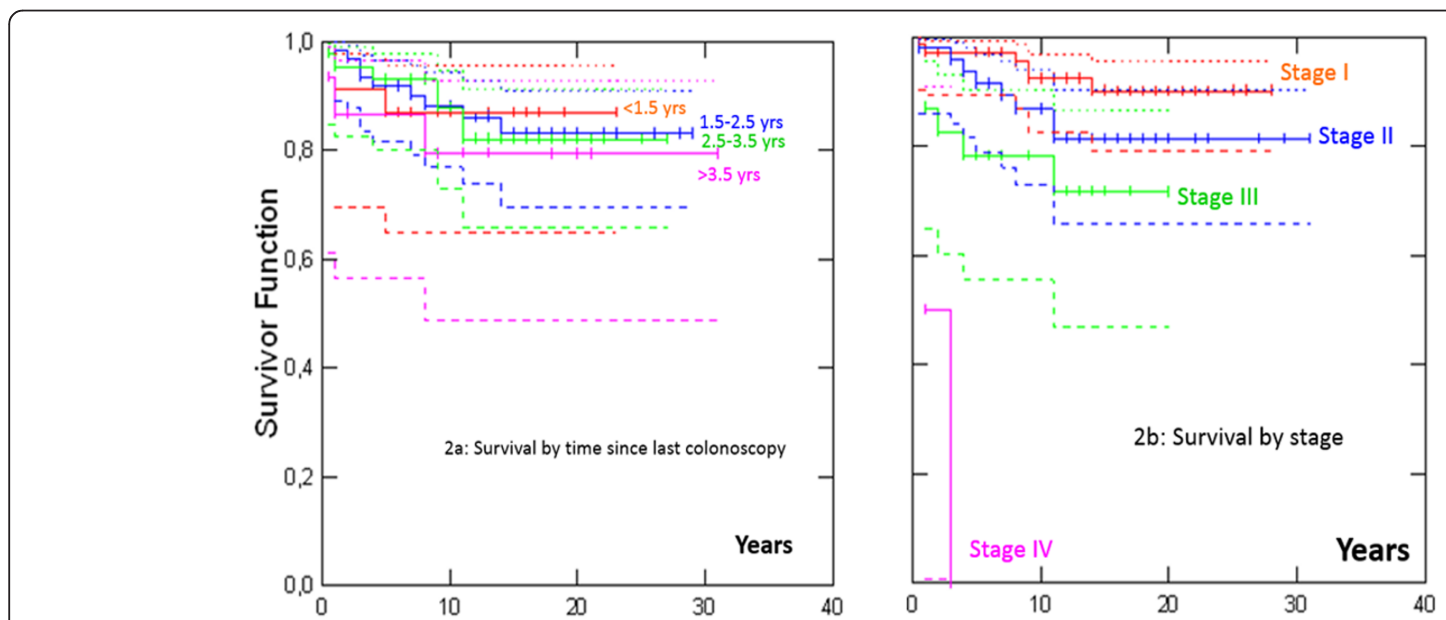

Fig. 2 Survival after colon cancer in 143 path_MMR carriers under 65 years of age with or without prior or prevalent cancer in any other organ 
aim to prevent colon cancer in path_MMR carriers. Our data may therefore be useful in formulating future revisions to clinical guidelines for LS.

In our study, the survival analyses included only colon and not rectal cancers. There were several reasons for this, including differences in the treatment, classification and time from diagnosis to surgical resection of rectal cancers (e.g. this can vary from immediate to delays of several months due to neoadjuvant therapy). In addition, wide variation in the treatment choices across different regions/countries have been described [13]. Since these differences may be confounders to our chosen endpoint, survival by stage, we decided to perform survival analysis only in colon cancers. It is, however, of utmost importance to also report these measures for rectal cancer separately. To achieve this, we will need to collate data for more rectal cancer cases than are currently reported to the PLSD.

There are several limitations to the current study. Numbers included are limited. All centres previously having contributed to the PLSD reports were invited to participate, but not all provided data to this report. We present no information on survival after a second colon cancer subsequent to a first colon cancer. It is possible that some existing lesions were missed during earlier colonoscopies that preceded the diagnosis of colon cancers. We have not excluded that colonoscopy with new techniques and better knowledge on what to look for may prevent cancer and improve survival, but even if so it still remains to be demonstrated that such is possible to implement in a broader health care setting: what we report is the observed outcome of health care so far, not what putatively might have been obtained otherwise. However, if colonoscopy quality did play a significant role related to survival, the impact might be expected to be greatest for the lesions missed with a three-yearly strategy, and survival would be expected to be worse in that group. Because we have recently shown that there is no significant difference between AJCC stages of cancers diagnosed when colonoscopies are done yearly or three-yearly, and as annual colonoscopy has been implemented more recently, there is no reason to assume that colonoscopies with short intervals were of lower quality. We restricted our analysis to the core subset of 96 carriers described to provide a robust crude survival analysis for colon cancer in path_MMR carriers with as few confounders as possible, and we found the same results when also including cases with prior or prevalent cancers in other organs.

While we report the largest prospective analysis undertaken so far of colon cancer survival in LS patients according to time since last colonoscopy, we do not, based on the current and our previous reports, advocate any revision of current clinical guidelines, and the PLSD will ask more contributors to provide data to repeat this study in an independent data set. More detailed studies are needed to understand why there are still some carriers dying from colon cancer, and how this may be prevented. Health economic studies are indicated to establish whether colonoscopy more frequently than every 3 years is justified from a resource perspective. These studies require data on the costs from all aspects, including unwanted (side-) effects, borne by health care systems and patients. The PLSD is presenting some of the many pieces of evidence that need consideration in discussions to revise current clinical guidelines for LS surveillance.

\section{Abbreviations \\ AJCC: American Joint Committee on Cancer; CRC: colorectal cancer; LS: Lynch syndrome; path_MLH1: Pathogenic (disease-causing) variant of the MLH1 gene; path_MMR: Pathogenic (disease-causing) variant of any mismatch-repair gene; path_MSH2: Pathogenic (disease-causing) variant of the MSH2 gene; path_MSH6: Pathogenic (disease-causing) variant of the MSH6 gene; path_PMS2: Pathogenic (disease-causing) variant of the PMS2 gene}

\section{Acknowledgements}

We would like to express our gratitude to Heikki Järvinen, Beatriz Alcala-Repo and Marianne Haeusler for their efforts during the years.

\section{Authors' contributions}

MDV, TTS and PM designed the study, drafted the manuscript, collected the feedback and revised the manuscript accordingly. PM conducted the statistical analysis. PM and MD-V managed the PLSD data. All authors participated in PLSD data collection. All authors read, critically commented, and approved the final manuscript.

\section{Funding}

TTS and J-PM are supported by the Emil Aaltonen Foundation, the Finnish Medical Foundation, the Instrumentarium Science Foundation, Sigrid Juselius Foundation, The Finnish Cancer Foundation, Jane and Aatos Erkko foundation and State Research Funding.

DGE and EJC are both supported through the National Institute for Health Research Manchester Biomedical Research Centre (IS-BRC-1215-20007).

The Spanish contribution: GC and MP were funded by the Spanish Ministry of Economy and Competitiveness and cofunded by FEDER funds -a way to build Europe- (grant SAF2015-68016-R) and the CIBERONC, the Carlos III Health Institute, the Scientific Foundation Asociación Española Contra el Cáncer and the Government of Catalonia.

The Welsh Contribution: Wales Gene Park.

The Norwegian contribution: Norwegian Cancer Society, contract $194751-$ 2017 for funding.

Work relevant for the German contribution was funded in part by Wilhelm Sander Foundation (2016.056.1) and German Research Foundation (Deutsche Forschungsgemeinschaft, DFG; KFO227, KL2354).

The study sponsors did not have a role in planning the study design; in the collection, analysis, or interpretation of data; in the writing of the report; or in the decision to submit the paper for publication.

\section{Availability of data and materials}

The datasets used and/or analysed during the current study are available from the corresponding author on reasonable request. We have published a website www.Iscarisk.org on which cancer risks for all published data can be reviewed and calculated in graphic form.

\section{Ethics approval and consent to participate}

All reporting centers obtained informed consent for genetic testing and surveillance procedures. De-identified data was exported for the current study. No named registry needing approval was established for the current study. 


\section{Consent for publication}

Not applicable.

\section{Competing interests}

Toni Seppälä: a co-owner (20\%) of Healthfund Finland Oy (educational and health care services in Finland, not related to patients or scope of this manuscript). Travel costs to a scientific meeting by Medtronic Finland. John Burn: a patent for high speed low cost tumor profiling pending to John Burn and QuantuMDx.

All others: None declared.

\section{Author details}

'Department of Tumor Biology, Institute of Cancer Research, Oslo University Hospital, Oslo, Norway. ${ }^{2}$ Department of Gastrointestinal Surgery, Helsinki University Central Hospital, Helsinki, Finland. ${ }^{3} \mathrm{Cl}$ inicum, University of Helsinki, Helsinki, Finland. ${ }^{4}$ Division of Cancer and Genetics, Institute of Medical Genetics, Cardiff University School of Medicine, Cardiff, UK. ${ }^{5}$ The Royal Melbourne Hospital, Melbourne, Australia. ${ }^{6}$ University of Melbourne, Melbourne, Australia. ${ }^{7}$ University of Manchester \& Manchester University Hospitals Foundation Trust, Manchester, UK. ${ }^{8}$ University of Newcastle and the Hunter Medical Research Institute, Callaghan, Australia. ${ }^{9}$ University of Newcastle, Newcastle upon Tyne, UK. ${ }^{10}$ University Witten-Herdecke, Wuppertal, Germany. ${ }^{11}$ Department of Surgical Gastroenterology, Aalborg University Hospital, Aalborg, Denmark. ${ }^{12}$ Central Finland Central Hospital, Education and Research, Jyväskylä, Finland. ${ }^{13}$ Research Programs Unit, Genome-Scale Biology, University of Helsinki, Helsinki, Finland. ${ }^{14}$ Karolinska Institutet, Stockholm, Sweden. ${ }^{15}$ St Mark's Hospital, Department of Surgery and Cancer, Imperial College London, London, UK. ${ }^{16}$ University of Manchester and St Mary's Hospital, Manchester, UK. ${ }^{17}$ Hereditary Cancer Program, Catalan Institute of Oncology, Insititut d'Investigació Biomèdica de Bellvitge (IDIBELL), ONCOBELL Program, L'Hospitalet de Llobregat, Barcelona, Spain. ${ }^{18}$ Centro de Investigación Biomédica en Red de Cáncer (CIBERONC), Madrid, Spain. ${ }^{19}$ Department of Clinical Genetics, Vejle Hospital, Vejle, Denmark. ${ }^{20}$ Department of Surgery, Regional Hospital West Jutland, Egtved, Denmark. ${ }^{21}$ Department of Oncology, Aalborg University Hospital, Aalborg, Denmark. ${ }^{22}$ Department of Pathology, Herlev Gentofte University Hospital, Herlev, Denmark. ${ }^{23}$ High Risk and Gl Cancer prevention Clinic, Gatro-Oncology Unit, The Department of Gastroenterology, Sheba Medical Center, Ramat Gan, Israel. ${ }^{24}$ Leids Universitair Medisch Centrum, Leiden, Netherlands. ${ }^{25}$ Center for Bioinformatics, Department of Informatics, University of Oslo, Oslo, Norway. ${ }^{26}$ Department of Clinical Genetics, Aarhus University Hospital, Aarhus, Denmark. ${ }^{27}$ Department of Applied Tumor Biology, Institute of Pathology, University Hospital Heidelberg, Heidelberg, Germany. ${ }^{28}$ Cooperation Unit Applied Tumor Biology, German Cancer Research Center (DKFZ), Heidelberg, Germany. ${ }^{29}$ Department of Health Sciences Research, Mayo Clinic, Scottsdale, AZ, USA. ${ }^{30}$ Medizinische Klinik und Poliklinik IV, Campus Innenstadt, Klinikum der Universität München, Munich, Germany. ${ }^{31}$ MGZ- Medical Genetics Center, Munich, Germany. ${ }^{32}$ Department of Surgery, Central Finland Central Hospital, Jyväskylä, Finland. ${ }^{33}$ Faculty of Sport and Health Sciences, University of Jyväskylä, Jyväskylä, Finland.

Received: 1 June 2019 Accepted: 11 September 2019

Published online: 14 October 2019

\section{References}

1. Syngal S, Brand RE, Church JM, Giardiello FM, Hampel HL, Burt RW, et al. ACG clinical guideline: genetic testing and management of hereditary gastrointestinal cancer syndromes. Am J Gastroenterol. 2015;110(2):223-62 quiz 63.

2. Seppala TT, Ahadova A, Dominguez-Valentin M, Macrae F, Evans DG, Therkildsen C, et al. Lack of association between screening interval and cancer stage in lynch syndrome may be accounted for by over-diagnosis; a prospective lynch syndrome database report. Hered Cancer Clin Pract. 2019;17:8.

3. Engel C, Vasen HF, Seppala T, Aretz S, Bigirwamungu-Bargeman M, de Boer SY, et al. No difference in colorectal Cancer incidence or stage at detection by colonoscopy among 3 countries with different lynch syndrome surveillance policies. Gastroenterology. 2018;155(5):1400.

4. Dominguez-Valentin M, Sampson JR, Seppälä TT, Ten Broeke SW, Plazzer JP, Nakken S, Engel C, Aretz S, Jenkins MA, Sunde L, Bernstein I, Capella G, Balaguer F, Thomas H, Evans DG, Burn J, Greenblatt M, Hovig E, de Vos Tot Nederveen Cappel WH, Sijmons RH, Bertario L, Tibiletti MG, Cavestro GM,
Lindblom A, Della Valle A, Lopez-Köstner F, Gluck N, Katz LH, Heinimann K, Vaccaro CA, Büttner R, Görgens H, Holinski-Feder E, Morak M, Holzapfel S, Hüneburg R, Knebel Doeberitz MV, Loeffler M, Rahner N, Schackert HK, Steinke-Lange V, Schmiegel W, Vangala D, Pylvänäinen K, Renkonen-Sinisalo L, Hopper JL, Win AK, Haile RW, Lindor NM, Gallinger S, Le Marchand L, Newcomb PA, Figueiredo JC, Thibodeau SN, Wadt K, Therkildsen C, Okkels H, Ketabi Z, Moreira L, Sánchez A, Serra-Burriel M, Pineda M, Navarro M, Blanco I, Green K, Lalloo F, Crosbie EJ, Hill J, Denton OG, Frayling IM, Rødland EA, Vasen H, Mints M, Neffa F, Esperon P, Alvarez K, Kariv R, Rosner G, Pinero TA, Gonzalez ML, Kalfayan P, Tjandra D, Winship IM, Macrae F, Möslein G, Mecklin JP, Nielsen M, Møller P. Cancer risks by gene, age, and gender in 6350 carriers of pathogenic mismatch repair variants: findings from the Prospective Lynch Syndrome Database. Genet Med. 2019. https:// doi.org/10.1038/s41436-019-0596-9.

5. Perrod G, Samaha E, Rahmi G, Khater S, Abbes L, Savale C, et al. Impact of an optimized colonoscopic screening program for patients with lynch syndrome: 6-year results of a specialized French network. Ther Adv Gastroenterol. 2018;11:1756284818775058.

6. Moller P, Seppala T, Bernstein I, Holinski-Feder E, Sala P, Evans DG, et al. Cancer incidence and survival in lynch syndrome patients receiving colonoscopic and gynaecological surveillance: first report from the prospective lynch syndrome database. Gut. 2017;66(3):464-72.

7. Moller P, Seppala T, Bernstein I, Holinski-Feder E, Sala P, Evans DG, et al. Incidence of and survival after subsequent cancers in carriers of pathogenic MMR variants with previous cancer: a report from the prospective lynch syndrome database. Gut. 2017;66(9):1657-64.

8. Seppala T, Pylvanainen K, Evans DG, Jarvinen H, Renkonen-Sinisalo L, Bernstein I, et al. Colorectal cancer incidence in path_MLH1 carriers subjected to different follow-up protocols: a prospective lynch syndrome database report. Hered Cancer Clin Pract. 2017;15:18.

9. Moller P, Seppala TT, Bernstein I, Holinski-Feder E, Sala P, Gareth Evans D, et al. Cancer risk and survival in path_MMR carriers by gene and gender up to 75 years of age: a report from the prospective lynch syndrome database. Gut. 2018;67(7):1306-16.

10. Møller P, Dominguez-Valentin M, Rødland EA, Hovig E. Causes for Frequent Pathogenic BRCA1 Variants Include Low Penetrance in Fertile Ages, Recurrent De-Novo Mutations and Genetic Drift. Cancers (Basel). 2019;11(2). https://doi.org/10.3390/cancers11020132.

11. Ahadova A, Gallon R, Gebert J, Ballhausen A, Endris V, Kirchner M, et al. Three molecular pathways model colorectal carcinogenesis in lynch syndrome. Int J Cancer. 2018;143(1):139-50.

12. Seth S, Ager A, Arends MJ, Frayling IM. Lynch syndrome - cancer pathways, heterogeneity and immune escape. J Pathol. 2018;246(2):129-33.

13. van den Broek CB, van Gijn W, Bastiaannet E, Moller B, Johansson R, Elferink $M A$, et al. Differences in pre-operative treatment for rectal cancer between Norway, Sweden, Denmark, Belgium and the Netherlands. Eur J Surg Oncol. 2014;40(12):1789-96

\section{Publisher's Note}

Springer Nature remains neutral with regard to jurisdictional claims in published maps and institutional affiliations.

\section{Ready to submit your research? Choose BMC and benefit from:}

- fast, convenient online submission

- thorough peer review by experienced researchers in your field

- rapid publication on acceptance

- support for research data, including large and complex data types

- gold Open Access which fosters wider collaboration and increased citations

- maximum visibility for your research: over $100 \mathrm{M}$ website views per year

At BMC, research is always in progress.

Learn more biomedcentral.com/submissions 